Cuadernos de Trabajo Social

ISSN: 0214-0314

\title{
Editorial: A paso de caracol se alcanza antes la meta
}

[en] At a snail pace a goal cin be reached faster

El año entrante se cumplirán veinticinco años desde que, en 1993, se creara en París la versión social del Service d'Aide Médicale Urgente (SAMU) o Servicio de Atención Médica de Urgencia. El fundador del SAMU-SOCIAL era el doctor Xavier Emmanuelli, un militante comunista y anticolonialista, médico, hijo y hermano de médicos que, veintidós años antes, había sido cofundador junto a otras doce personas de la organización Médicos sin fronteras. La importantísima labor llevada a cabo desde entonces por el Samu-Social, cuyo objetivo era "salir al encuentro de las personas que vivían en la calle en situación de pobreza y riesgo físico y social", continúa realizándose no solo en Paris, sino en otras muchas grandes ciudades de todo el mundo, Madrid entre ellas. Con el Samu-Social parisino se iniciaba, a principios de los años noventa, el camino en expansión constante de esta lógica de la emergencia que trasladó el modelo de urgencias sanitario al campo de lo social y abrió paso a la introducción de los servicios de emergencia en el mundo de la intervención y el Trabajo Social.

Andando el tiempo, sin embargo, las luces de estos servicios de urgencia o emergencia, han ido alternándose con las sombras que una política social cicatera, cortoplacista y de horizontes limitados ha ido imponiendo aquí y allá, en un contexto general de crisis y recortes sociales; recortes presupuestarios que, entre otras cosas, llevaron a Emmanuelli a presentar su dimisión como presidente del Samu-Social, en julio de 2011. Con ello se hizo patente la crisis profunda que vive actualmente la lógica de la emergencia-urgencia, cuando se intenta llevar a cabo de forma seria y consecuente, en un momento histórico marcado por un escandaloso crecimiento de la desigualdad y el desempleo masivo, cuando la pobreza y la ex- clusión pasan a afectar a millones de personas y no son solo problemas que, como ocurría en el pasado, aunque eran agudos y graves afectaban únicamente a pequeños grupos de población marginal que habitaban a la intemperie en el corazón de nuestras grandes ciudades.

Entretanto, la opinión pública se ha vuelto cada vez más receptiva y sensible a un tipo de actuación de los poderes públicos orientada por esta lógica de la emergencia, que es percibida por el ciudadano medio como un tipo de política realmente eficaz frente a catástrofes de origen más o menos azaroso e impredecible. De manera que, al igual que se multiplican los dispositivos de intervención rápida - en caso de incendios forestales, de atentados terroristas o accidentes con gran número de víctimas, de naufragios desastrosos, como el del Prestige, con enorme impacto ecológico, o en caso de situaciones dramáticas como en la llamada "crisis de los refugiados" - también en el campo de lo estrictamente social, se espera que la Administración Pública lleve a cabo una intervención contundente, rápida y resolutiva que solucione el problema con celeridad y prontitud; se espera, además, que lo haga de forma claramente visible, manifiesta y pública para todo el mundo, reclamando la intervención espectacular de una especie de "bomberos de lo social" que, como en el caso de la Unidad Militar de Emergencia (UME) por ejemplo, resuelva de un día para otro el espectáculo insoportable de la miseria que se exhibe en los telediarios, los periódicos y las calles de nuestras sociedades de abundancia.

Esta necesidad de actuar, dejándose ver ante la opinión pública que se ha ido abriendo paso en muchos ámbitos de la realidad social y política, permite añadir al espectáculo del problema, que se nos muestra en los medios de comunicación de forma más o menos este- 
reotipada, la espectacularidad del despliegue de medios físicos, vehículos y profesionales, que son movilizados por el poder para solucionar cualquier situación de crisis. Un poder que, mediante tan despliegue de medios materiales y humanos, se muestra fuerte, vigoroso y cuasi omnipotente a la hora de velar por nosotros, los ciudadanos. Todo ello en un mundo donde la multiplicación de los riesgos percibidos (Beck, 2002), propicia la actuación política orientada a "educar" permanentemente a la población en la incertidumbre y el temor, y a arbitrar un tipo de soluciones que inevitablemente escapan a los simples ciudadanos particulares, ya que corresponden exclusivamente a las altas instancias del poder, debido a la cuantía de recursos que requieren, al carácter jerárquico que gobierna su funcionamiento y (¿por qué no decirlo?) a los previsibles réditos electorales que se espera generar con ellas. En la práctica, la lógica de la emergencia social de alas recortadas que condujo a la dimisión de Xavier Emmanuelli en París, se ha hecho funcionar en muchos lugares como parte de una estrategia de marketing político, orientada a encubrir los retrocesos en materia de política social -una política social asentada en la lógica de los derechos y la universalidad - y ha corrido en paralelo con una fuerte desmovilización social, ya que apenas si demanda de la ciudadanía la complicidad para detectar las situaciones de urgencia, llamando al 112, pero que quizás, por eso mismo, a continuación renuncia a actuar y demandar de los responsables políticos una política que incida sobre las causas estructurales, profundas y a largo plazo de los problemas (de empleo, vivienda, pobreza, etc.) que subyacen tras las denuncias presentadas.

Como han puesto de relieve algunos autores que han censurado la expansión acrítica de esta lógica de la emergencia en el ámbito de la intervención social, la demanda de estos servicios de gestión urgente y rápida de la exclusión social ha implicado la "aparición de un nuevo dispositivo global de gestión de las precariedades, al que debería ajustarse un nuevo tipo de sujeto, ciertamente activo pero siempre sujetado (Francq, 2005, p. 291). Con ello se ha adulterado profundamente, la inspiración inicial de aquellos "empresarios morales" de Becker, procedentes de la sociedad civil que, como en el caso de Emmanuelli, Pedro Meca y tantos otros, propiciaron la aparición de estos servicios destinados a intervenir, con medios suficientes y adaptados, en los casos más dra- máticos de pobreza y exclusión. Unas iniciativas pioneras que intentaban ser un atajo para lograr la priorización de estos temas tradicionalmente postergados dentro de una agenda de política social pública que a día de hoy continúa siendo a menudo inexistente como tal política pública. Así se demuestra en el hecho de que la mayor o menor "urgencia de las urgencias" siga estando vinculada a las estaciones del año (al alza en invierno, a la baja en verano), a la irrupción en los medios de noticias más o menos cargadas de morbo y sensacionalismo, o a la proximidad o lejanía de los procesos electorales.

Otros aspectos cuestionables de esta lógica de la emergencia son los que surgen de su vinculación con un enfoque economicista basado en el análisis coste-beneficio estimado a corto plazo, con lo que se desdeña o se prescinde por completo del carácter crónico, cuando no permanente, de algunas situaciones que, siendo estables y prolongadas, se abordan sin embargo con estos dispositivos "de emergencia". Situaciones de dificultad y exclusión que, por su misma naturaleza y por los límites estructurales que vienen impuestos por el modelo de sociedad actual, resultan absolutamente imposibles de resolver en cuestión de semanas o en unos pocos meses. Pensemos en el difícil asunto del acceso a la vivienda, del desempleo juvenil o de los mayores de 50 años, la integración de grupos étnicos en grave marginación, etc. En casi todos los procesos de extrema pobreza, la dimensión temporal del acompañamiento (Wolff, 2017) es un componente básico a tener en cuenta, si se quieren consolidar los resultados y lograr efectos duraderos y permanentes, con lo cual no resulta fácil imponer esta otra lógica de la urgencia y la rapidez, que conlleva preestablecer de antemano tiempos estrictos de salida de los recursos, o períodos muy breves de intervención intensiva que, a la postre, encima casi nunca se cumplen.

Esta filosofía de la prisa y el logro de resultados inmediatos se inscribe obviamente dentro de la lógica general de un sistema capitalista, en donde la lucha contra el tiempo, concebido como un enemigo a batir y domeñar ha pasado a ser un componente esencial de la producción de bienes y servicios, y un factor clave en la generación de beneficios para las empresas. Habida cuenta de que muchos de estos servicios de emergencia, si bien surgieron vinculados a propuestas de organizaciones sociales de carácter no lucrativo, han termi- 
nado por ser gestionados por empresas, o con criterios puramente empresariales, generar resultados en el menor tiempo posible y al menor coste que se puedan permitir ha pasado a ser el objetivo principal de actuación. Quizás por ello, del mismo modo que hay que obtener resultados rápidos, se necesita contar con trabajadores dispuestos a moverse con ligereza y prontitud en medio de un laberinto de contratos breves, temporales, por horas, discontinuos, etc. La paradoja de intentar luchar contra la precariedad, creando precariedad (laboral), vuelve doblemente difícil el papel de los profesionales de las emergencias, obligados a trabajar con prisas y en el día a día, sin poder consolidar una carrera profesional a medio y largo plazo, u obligados a ofrecer respuestas puntuales e inmediatas ante casos tan tremendamente complejos que requerirían un acompañamiento continuado y duradero. Todo lo cual, se traduce a menudo, en insatisfacción, desánimo y burnout.

$\mathrm{Si}$, en general, las prisas no suelen ser buenas en la vida, cuando se trata de realizar un Trabajo Social de calidad se convierten en un gravísimo inconveniente. Entre otras cosas, porque responden más a la presión de la organización y de las instituciones sobre sus profesionales que a los requisitos emanados de la propia metodología de intervención, y mucho menos aún a los deseos o las expectativas de los usuarios de los servicios con quienes trabajamos, personas que por lo general se presentan ante nosotros con unos ritmos vitales y un tempo biográfico que difícilmente se acomoda a nuestro plan de trabajo o a nuestros calendarios, con lo cual pasan a convertirse en un obstáculo a salvar, un inconveniente a evitar, un objeto a desplazar, que con esa expansiva lógica de la macdonaldización, como en los restaurantes de comida rápida, terminan siendo despojados de su condición de sujetos activos, con los que el establecimiento de relaciones duraderas de intercambio y reciprocidad, de reflexión compartida y de participación crítica solo representa una estúpida pérdida de tiempo.
Creemos firmemente que recuperar el verdadero sentido de la emergencia social supone inscribirla en una intervención de largo recorrido y asentada sobre una lógica de derechos ciudadanos universalmente defendibles; no en actuaciones de cara a la galería o basadas en el carácter más o menos arbitrario de la elegibilidad discrecional en razón de cuál sea el nivel de gravedad de una crisis que se supone puntual y momentánea. Para que sea legítima, una intervención urgente ha de estar enmarcada siempre en una política estructural y de paso lento. Contra el vicio de la rapidez, hay que volver a reivindicar la virtud de la lentitud (Gallardo, 2002). A fin de cuentas, si nos remontamos a los orígenes de la emergencia social en las ciudades modernas, nos encontramos con que casi por las mismas fechas en las que se fundó en París el Samu-Social, el sociólogo y periodista italiano, Sandro Pertini, presentaba también en París, en 1989, el movimiento internacional Slow Food, una iniciativa surgida como reacción alternativa de reivindicación del estilo de vida mediterráneo ante la instalación, en la Piazza de Spagna de Roma, de un restaurante de comida rápida de la más conocida marca de hamburguesas norteamericana, líder mundial de la fast-food. Este movimiento, aglutina en este momento a millones de personas repartidas por más de 80 países, y cuenta en la actualidad con unos cien mil socios entre cocineros, agricultores, ganaderos, pescadores, comunidades indígenas y campesinas, etc.; está empeñado en reivindicar, como alternativa viable y sostenible frente a la rapidez y la estandarización industrial, las bondades del trabajo artesano y de la lentitud en la comida y la gastronomía, el urbanismo y el transporte (Slow Cities), por eso mismo escogió como logotipo para Slow Food (https://www.slowfood.com) la imagen de un caracol, figura de caminar parsimonioso pero seguro, que bien podría ser reclamada también para reivindicar el derecho a disfrutar de un Trabajo Social lento, cachazudo y sostenido en el tiempo.

\section{Referencias bibliográficas}

Beck, U. (2002). La sociedad del riesgo global. Madrid: Siglo XXI.

Francq, B. (2005). Citoyenneté et urgence sociale: la figure dus sans-abrisme. En: D. Ballet, Les SDF: visibles, proches, citoyens (pp. 289-300). París: PUF. 
Gallardo, M. Á. (3 de marzo de 2002). Contra el vicio de la rapidez, la virtud de la lentitud. Recuperado de: Afuegolento: http://www.afuegolento.com/articulos/1074/contra-el-vicio-de-la-rapidez-la-virtudde-la-lentitud

Wolff, V. (2017). Visibilité et invisibilité de l'urgence dans les politiques sociales. Journal Européen d'Education Sociale, 28-29, 20-30.

Pedro Cabrera Cabrera y Luis Nogués Sáez directores 